\title{
Estado actual das investigacions sobre lírica galego-portuguesa (O Arquivo Galicia Medieval)
}

\author{
Mercedes BreA
}

Universidad de Santiago

Desde que a comezos deste século publicara Dna. Carolina Michaëlis de Vasconcelos o seu monumental estudio e edición do Cancioneiro da Ajuda ${ }^{1}$ foron aparecendo edicións do corpus lírico galego-portugués organizadas por xéneros ${ }^{2}$, pero tamén por trobadores, algúns dos cales mereceron a atención de máis dun investigador ${ }^{3}$, e mentras que outros esperan aínda por unha atención particularizada ${ }^{4}$.

No campo dos estudios literarios, ademais dos traballos de M. Rodrigues Lapa ou X. Filgueira Valverde, entre outros, marcou un fito decisivo a aparición da análise de conxunto efectuada por $\mathrm{G}$. Tavani ${ }^{5}$ — precedida polo repertorio métrico realizado polo mesmo investigador - , unha análise que actualmente está sendo revisada e completada nos volumes que Edicións Xerais de Galicia está dedicando a cada un dos xéneros?

' MAX Niemeyer, Halle, 1904. Reimpresión en Imprensa Nacional-Casa da Moeda, Lisboa, 1990, incorporando o glosario que aparecera á parte, na Revista Lusitana.

${ }^{2}$ Cfr. J. J. Nunes, Cantigas d' amigo dos trovadores galego-portugueses, ed. crítica, acompanhada de introdução, comentário, variantes e glossário, 3 vols., Coimbra, 1926-1928 (con varias reimpresións posteriores); do mesmo autor, Cantigas d'amor dos trovadores galego-portugueses, Coimbra, 1932 (con varias reedicións); M. Rodrigues LAPA, Cantigas d' escarnho e de mal dizer dos Cancioneiros medievais galego-portugueses, $2^{\mathrm{a}}$ ed., Galaxia, Vigo, 1970.

'Recordemos, por ex., o caso de Pero da Ponte, para o que hai unha edición de R. FERNÁNDE/ Pousa, outra de S. Panunzjo e outra de A. Juarez Blanqler; ou o de Pero Meogo, con edicións de A. F. G. Bell, L. A. de Azevedo Filho e X. L. Méndez Ferrín.

${ }^{4}$ Non deixa de ser curiosa a constatación de que as edicións por xéneros son debidas a investigadores de ámbito portugués, mentres que a maior parte das edicións de trobadores individuais acusan a impronta da escola filolóxica italiana.

"La poesia lirica galego-portoghese, vol. II. t. I, fasc. 6 le La lyrique galicienne-portugaise (partie documentaire), vol. II, t. I., fasc. 8] do Grundriss der romanischen Literaturen des Mittelalters, Carl Winter, Heidelberg, 1980. Hai traducción galega na editorial Galaxia, Vigo, 1986, e portuguesa, en Comunicação, Lisboa, 1990.

${ }^{6} G$. Tavani, Repertorio metrico della lirica galego-portoghese. Ed. dell'Ateneo, Roma, 1967.

'Ata o momento, apareceron os correspondentes ás cantigas de amor e de escarnio e maldecir: V. Beltrán, A cantiga de amor. Xerais, Vigo, 1995; G. Lanclani-G. Tavanl, As cantigas de escarnio. 
Non menos importante para o coñecemento deses textos trobadorescos foi a aparición das edicións facsimilares dos tres grandes cancioneiros, a última (a do cancioneiro da Ajuda) bastante recente aínda ${ }^{8}$.

Complementariamente, foron aparecendo antoloxías dos textos líricos, acompañadas de notas aclaratorias de enorme interese, e, nalgún caso, revisando as edicións existentes ${ }^{9}$

Ademais, para unha comprensión global dos cancioneiros, resultan xa imprescindibles os estudios de A. Ferrari ${ }^{10} \mathrm{e}$ E. Gonçalves ${ }^{11}$, ampliados recentemente por A. Resende de Oliveira ${ }^{12}$, que presenta unha fonda reflexión sobre o proceso de compilación da tradición manuscrita galego-portuguesa e sobre os datos históricos relativos ós autores.

Con todo esto, poderiamos resumi-lo panorama actual dos estudios sobre a nosa lírica medieval dicindo que dispoñemos de edicións críticas individuais (aínda que son moitas as que faltan por facer) e colectivas (ningunha da totalidade do corpus ata a aparición dos dous volumes da Lírica profana galego-portuguesa ${ }^{13}$ ) e de estudios de conxunto, e tamén sobre temas particulares ${ }^{14}$, relativos ós aspectos literarios, e tamén ós puramente filolóxicos. De presentación actualizada de todos eses coñecementos acadados pode servirnos o Dicionário da Literatura Medieval Galega e Portuguesa, organizado e coordenado por Giulia Lanciani e Giuseppe Tavani ${ }^{15}$.

Sen embargo, esta proliferación de traballos (non todos de fácil acceso, por outra parte) permite tamén facer unha reflexión sobre as moitas puntuali-

Xerais, Vigo, 1995. Case en paralelo, a Asociación Socio-Pedagóxica Galega publicou en fascículos sendas antoloxías e estudios, tamén por xéneros (A Nosa Terra, Vigo, 1996).

${ }^{8}$ Cancioneiro Português da Biblioteca Vaticana (Cod. 4803), Centro de Estudos Filológicos-Instituto de Alta Cultura, Lisboa, 1973; Cancioneiro da Biblioteca Nacional (Colocci-Brancuti). Cód. 10991. Biblioteca Nacional/Imprensa Nacional-Casa da Moeda, Lisboa, 1982; Cancioneiro da Ajuda, Edições Távola Redonda, Lisboa, 1994.

${ }^{4}$ Mencionaremos só algunhas das máis difundidas: X. M. Álvarez BlázQuez, Escolma da poesía medieval (1198-1354), Ed. Castrelos, Vigo, 1975; C. Alvar-V. Beltrán, Antología de la poesía gallego-portuguesa, Alhambra, Madrid, 1989 (reimpresión); E. GonÇALVES-M ${ }^{\mathrm{a}} \mathrm{A}$. RAMOS, A lírica galego-portuguesa (Textos escolhidos), Ed. Comunicação, Lisboa, 1983.

${ }^{10}$ A. FERRARI, "Formazione e struttura del Canzoniere Portoghese della Biblioteca Nazionale di Lisbona (Cod. 10.991: Colocci-Brancuti)", Arquivos do Centro Cultural Português, 14, 1979, pp. 27. 142 .

" E. Gonçalves. "La Tavola colocciana 'Autori Portoghesi'”, Arquivos do Centro Cultural Português, 10, 1976, pp. 387-406.

12 Despois de varios artículos sobre aspectos concretos da transmisión, recolleu as súas conclusións en Depois do espectáculo trovadoresco. A estrutura dos cancioneiros peninsulares e as recolhas dos séculos XIII e XIV. Colibri, Lisboa, 1994; e Trobadores e xograres. Contexto histórico. Xerais, Vigo, 1995.

${ }^{13}$ Traballo realizado por un equipo de investigadores (F. MAGÁn ABElLEIRA, I. Rodiño CARAMÉS, $M^{a}$ C. Rodríguez Castaño, X. X. Ron Fernández, co apoio de A. Fernández Guidananes e $M^{a}$ C. VÁzQUEZ PACHO), coordinados por M. BREA, Xunta de Galicia (Centro de Investigacións Lingüísticas e Literarias "Ramón Piñeiro"), Santiago de Compostela, 1996.

${ }^{14}$ Basta con botar unha ollada ás actas dos congresos da Asociación Hispánica de Literatura Medieval para facerse unha idea da vitalidade de que gozan hoxe en día estes estudios.

is Publicado pola editorial Caminho, Lisboa, 1993 (= DI.MGP). 
zacións que aínda son posibles para un coñecemento máis completo do fenómeno trobadoresco. E, ó mesmo tempo, deixa patente unha carencia neste tipo de investigacións: non existe polo momento un estudio descritivo da lingua empregada polos trobadores ${ }^{16}$, por moito que algunhas das edicións críticas de autores individuais conteña notables achegas nese senso; nin tampouco un glosario completo dese corpus, aínda que boa parte das edicións (en particular, neste caso, entre as que abarcan un xénero, a de Michaëlis e a de Lapa) poidan contribuir a encher ese baleiro, e este poida ser suplido en parte polo glosario de R. Lorenzo que acompaña á súa edición da traducción galega da Primera Crónica General e da Crónica de Castilla ${ }^{17}$.

\section{O ARQUIVO GALICIA MEDIEVAL ${ }^{18}$}

Nos últimos anos, a aparición de textos medievais en formato electrónico (o exemplo máis próximo a nos é o Archivo Digital de Manuscritos y Textos Españoles (ADMYTE), editado pola empresa Micronet) fixo pensar a varios investigadores na conveniencia de agrupar tódolos textos conservados da tradición lírica galego-portuguesa nun grande arquivo electrónico que permitise a súa consulta áxil e facilitase a realización de novas investigacións sobre ese corpus. Pero, coma todo proxecto deste tipo, era preciso dispoñer de grandes recursos tecnolóxicos e humanos, polo que non foi posible abordalo dunha maneira definitiva ata a creación pola Xunta de Galicia dun grande centro de investigación en Humanidades.

Así, cando a Xunta de Galicia creou o Centro de Investigacións Lingüísticas e Literarias "Ramón Piñeiro" (daquí en diante, CIRP), confluiron nel dous proxectos de investigación que de contado se revelaron, á vez, parciais e complementarios: un, presentado por Vicente Beltrán, que pretendía aproveita-la experiencia recente de ADMYTE coa literatura española medieval para iniciar un proceso de dixitalización das fontes manuscritas, acompañadas dunha transcrición das mesmas (ou utilizando como alternativa as edicións existentes); outro, xa iniciado por Mercedes Brea, que pretendía agrupar en soporte electrónico tódolos textos conservados, ordenados segundo o Repertorio de Tavani e presentados na edición que, para cada cantiga, se considerase máis fiable. A finalidade deste segundo proxecto era doble: por unha parte, servir de instrumento para a docencia; pola outra, facilitar certo tipo de investigacións (busca de recursos formais, de motivos temáticos, estudios gramaticais e lexicográficos,

\footnotetext{
${ }^{16}$ Algo así como La lingua dei trovatori (occitanos) de A. RoncaGliA, Ed. dell'Ateneo, Roma, 1965.

${ }^{17}$ Cfr. R. LoRenzo, La traducción gallega de la Primera crónica general y de la Crónica de Castilla, Inst. de Estudios Orensanos "P. Feijoo", Orense, 1977.

${ }^{1 k}$ Este texto é unha versión revisada e actualizada da ponencia presentada no congreso sobre Testi, manoscritti, ipertesti medievali, organizado pola sismel en maio de 1996, en Florencia.
} 
etc.). Por tal motivo, queríase incorporar á presentación dos textos unha información que os complementase: unha ficha bio-bibliográfica de cada trobador ${ }^{19}$, unha relación das edicións principais de cada cantiga, a indicación do esquema métrico e das rimas ${ }^{20}$, a mención do xénero, do tema ou de motivos temáticos de interese, os principais recursos empregados tanto para liga-las estrofas como para enriquecer formalmente as cantigas, etc. Desexábase, en definitiva, proporcionar ós estudiosos unha serie de datos seleccionados sobre os que poder realizar análises de distintos tipos.

Cando os responsables do CIRP prestaron atención a eses dous proxectos, contemplaron a posibilidade non só de fundilos nun só, senón tamén de enriquecelos e amplialos. En diversas sesións de traballo - nas que participaron, sobre todo, Fernando Magán Muñoz (coordinador do equipo informático) e Guillermo Rojo (director técnico de Lingüística), pero tamén Anxo Tarrío (director técnico de Literatura) e, ocasionalmente, outros investigadores "externos" ó Centro, como David Mackenzie, Charles Faulhaber, Arthur Askins, Harvey Sharrer, Aida Fernanda Dias, ...--, foise fraguando un proxecto moito máis ambicioso: crear un arquivo de textos e de imaxes de manuscritos que abarcase, a ser posible, todo o ámbito medieval do galego, non só desde o punto de vista literario, senón tamén lingüístico, e incluso histórico, paleográfico, etc., polo que non se pode prescindir, por exemplo, dos documentos xurídicos e administrativos, incluso dos moitos que están aínda inéditos. Naceu así o Arquivo Galicia Medieval, que necesariamente había que subdividir en diversos apartados, porque era imposible acometelo de inmediato en todo o que supoñía.

Decidiuse axiña que a primeira parte que sería abordada sería a correspondente á Lírica galego-portuguesa ${ }^{21}$, por ser a que presentaba xa un mínimo deseño de partida e unhas necesidades que parecía posible delimitar, contando coa colaboración dun grupo de especialistas que, desde o primeiro momento, estiveron prestos a poñerse a disposición do proxecto e cos que se realizaron varias reunións de traballo. Entre os membos deste equipo asesor, que achegaron numerosas observacións e correccións e prestaron sempre un apoio incondicional ó proxecto, debemos mencionar a Carlos Alvar Ezquerra (Universidade de Alcalá de Henares), Valeria Bertolucci-Pizzorusso (Universidade de Pisa), Anna Ferrari (Universidade de L'Aquila), Luciano Formisano (Universidade de Bologna), Elsa Gonçalves (Universidade de Lisboa), Giulia Lanciani (Universidade La Sapienza, de Roma), Juan Paredes Núñez (Universidade de Granada) e Giuseppe Tavani (Universidade La Sapienza, de Roma).

${ }^{19}$ Elaborada fundamentalmente (en algúns casos, enriquecida con aportacións do seu redactor, $\mathrm{X}$. Ron) a partir dos libros de Michaëlis, Tavani e Resende xa mencionados, e máis dos datos fornecidos polo DLMGP.

${ }^{20} \mathrm{Na}$ mayoría dos casos, coinciden cos facilitados por Tavani no $R M$. De todos modos, hai diverxencias considerables, debidas fundamentalmente á existencia de novas edicións que apareceron con posterioridade á publicación do Repertorio.

${ }_{21}$ As outras tres previstas (non necesariamente nesta orde) son: a) Cantigas de Santa María, b) Prosa literaria e historiográfica, c) Prosa documental. 
O obxectivo dos múltiples encontros e reunións de traballo que houbo que realizar, non só co equipo de investigadores mencionados, senón, de maneira particular, entre os dous directores, o equipo de informáticos e o grupo de bolseiros que traballan a tempo completo no proxecto, era establece-las bases para almacena-los froitos dun inmenso traballo de estudio e investigación filolóxica e histórica, utilizando as tecnoloxías máis recentes e dotando ó arquivo de novos recursos, ademáis de aproveita-la enorme capacidade dos ordenadores para a recuperación convencional do texto. Para informatiza-la $L G P$, era necesario atopar unha metodoloxía de traballo que permitise satisfacer non só as esixencias manifestadas inicialmente polos filólogos, senón tamén tódalas necesidades que foron xurdindo a medida que se profundizaba na análise da información. Neste senso, os obxectivos revelábanse cada vez máis ambiciosos, polo que o grao de dificultade aumentaba progresivamente, e as planificacións teóricas que supoñían a perfecta solución de diversos problemas non sempre resultaban eficaces no momento de transformalas en realizacións prácticas.

O desenvolvemento do proxecto estivo sempre condicionado a dúas premisas básicas:

- as estructuras de información tiñan que ser abertas, para que os datos poidesen ser utilizados desde pontos de vista moi variados;

- había que atopar un xeito de representa-la información que fose independente tanto dos programas (software) coma do propio sistema físico empregado (hardware), preservando o material da obsolescencia tecnolóxica.

\section{DATOS TÉCNICOS}

A busca dos instrumentos electrónicos axeitados para levar a cabo un proxecto deste tipo supuxo un traballo inxente, porque as necesidades analizadas non permitían utilizar soportes convencionais. Por iso houbo que buscar sistemas de bases de datos, editores, visualizadores, etc., e todo no ámbito de terminoloxías emerxentes que aínda non son de uso frecuente.

A información contida na $L G P$ contén dous tipos de obxectos:

a) os textos, tanto na "edición de referencia" (que é a presentada no libro da Lírica profana galego-portuguesa, con tódalas limitacións que alí se especifican) coma nas distintas edicións críticas realizadas de xeito colectivo (por xéneros) ou individualizado (por trobadores);

b) as imaxes dos manuscritos conservados en bibliotecas diversas.

Polo que respecta ós textos, teñen que ser almacenados respectando una serie de restriccións. O traballo informático que había que desenvolver era, neste caso, a creación das estructuras que permitisen organizar e manipula-los textos seguindo unhas directrices, que nacen da mesma estructura lóxica do 
texto, pero tamén dos elementos de información que cada filólogo quere facer resaltar como relevantes. Por outro lado, se se quere respecta-lo traballo publicado polos autores das edicións existentes, hai que distinguir individual e colectivamente os elementos que eles distinguen, pero só eses. E non podemos esquecer que a manipulación informática ten que combina-la transparencia para o usuario (metainformación) coa mellor utilización dos elementos por parte dos programas (editores, motores de recuperación, etc.).

A integración das imaxes dos manuscritos realízase despois do oportuno proceso de dixitalización. Tanto este coma as operacións asociadas á inserción dependen dalgúns factores técnicos, pero están sometidos tamén a restriccións, na súa evidente dependencia dos resultados esperados.

\subsection{CODIFICACIÓN DO TEXTO}

A codificación electrónica efectúase desenvolvendo unha arquitectura que emprega unha representación concreta da información e do seu almacenamento, orientada cara ó contido e non á presentación. Para a creación de modelos orientados ó contido, decidiuse utilizar SGML (= Standard Generalized Markup Language), un estándar de representación e intercambio de información, que funciona como unha metalinguaxe (ten unha sintaxe, pero está privado de semántica, polo que quen o usa ten que proveelo desa semántica), e xera "linguaxes de marcas".

Toda aplicación en SGML consta de tres componentes:

a) unha "declaración" SGML, que almacena unha serie de parámetros empregados no contorno;

b) unha DTD (= definición de tipo de documento);

c) o propio documento (datos), inserto na chamada "instancia de texto".

A DTD contén as declaracións de linguaxe de marcas que utiliza esta aplicación e que dirixen a estructura da información durante o desenvolvemento do proceso de codificación, proceso que segue unha aproximación xerárquica dos contidos. A súa definición nace como resultado da análise do problema, despois de identificar qué elementos de investigación son considerados relevantes, e sen perder de vista qué investigacións haberá que realizar sobre o sistema cando estea almacenada toda a información.

Neste sistema, $L G P$ ten, nun primeiro nivel, dúas cabeceiras que conteñen información estructurada relativa á información xeral do proxecto (nome, grupo de traballo, responsables, dimensións do ficheiro nun momento dado, etc.), sen excluír elementos importantes, como a bibliografía xeral do proxecto. 
Nun segundo nivel de xerarquía, aparecen as edicións. Cada unha delas (a preparada polo CIRP, por unha banda, e as demáis - por xéneros e individuais--, pola outra) ten unha cabeceira de edición que inclúe os elementos de información comúns a tódalas cantigas ou textos críticos que constitúen a edición mesma.

Nun terceiro nivel, aparecen os "textos críticos", prolongados á súa vez por unha cabeceira de texto crítico, que inclúe tódolos elementos informativos comúns á cantiga que se codifica a continuación, é dicir: unha clave numérica que identifica o documento e corresponde ó número do trobador e número do poema; o tipo de cantiga (mestría / refrán); o número de estrofas; o xénero do poema; a indicación de se contén algún elemento nunha lingua diferente do galego-portugués; o incipit; os posibles problemas de atribución; a aclaración, cando procede, de que se trata dunha tensó, para facilita-lo enlace co segundo autor; as referencias dos manuscritos (sigla, número de cantiga, número de folio, anverso ou reverso); a indicación de se contén notación musical ou espacio para a mesma; a relación das edicións existentes, sinalando a que serve de base ó documento; os tipos de relación interestrófica; as notas coloccianas (cando as hai); posibles motivos temáticos identificados na cantiga (dunha relación preestablecida que contén 45 categorías e 13 subcategorías diferentes); rúbricas explicativas e comentarios ás rúbricas; finalmente, outros elementos misceláneos.

Os niveis subseguintes nacen da estructura particular dos contidos das estrofas, fiindas ou, no seu caso, refráns iniciais. O seu contido está constituido por versos e, no interior destes, ponse de manifesto cada un dos fenómenos considerados, desde un procedemento retórico a unha sinalefa, desde un topónimo a unha cesura. Así, precísanse en primeiro lugar datos como os relativos ó número de versos que configuran ese grupo, o esquema métrico e rítmico, e o número do esquema no $R M$ de Tavani. Segue o "corpo" do grupo propiamente dito: número do verso dentro do grupo, número de sílabas, rima, elemento en rima, patrón acentual ${ }^{22}$, texto do verso, coas notas que correspondan e os segmentos que sinalan fenómenos filolóxicos, métricos, rímicos, retóricos, etc.

\subsection{IMAXES DOS MANUSCRITOS}

Unha vez recoñecida a imposibilidade de recorrer a unha dixitalización directa das fontes nas sedes nas que se conservan, non queda outra solución que realizar ese proceso dun modo indirecto, atendendo a que non se trata só

2 Este é probablemente un dos elementos de información máis discutible, non só por non poder precisar en tódolos casos a entonación do verso, senón sobre todo por tratarse de "cancións", coas "distorsións" acentuais que pode provoca-la estructura musical. Aínda sí, optouse por deixalo por pensar que pode ter outras vantaxes dispoñer dese dato. 
de almacena-la imaxe dunha páxina ou dun detalle da mesma, senón que hai que atender á súa conservación dentro dunha base de datos, á posibilidade dunha visualización, á súa posible inclusión nun texto impreso, etc. Por razóns de varios tipos, entre as que ocupa un lugar preponderante a necesidade de obter unha alta resolución das imaxes, optouse por efectua-la dixitalización a partir de diapositivas de $35 \mathrm{~mm}$.

$\mathrm{O}$ feito de que almacena-la imaxe dun folio dun cancioneiro requira dimensións enormes crea problemas de almacenamento local, pero, ó mesmo tempo, condiciona notablemente a difusión destas imaxes a través das redes informáticas de área extensa, a causa da capacidade limitada dos enlaces.

\subsection{RECUPERACIÓN DA INFORMACIÓN}

O que dá sentido a un proxecto de informatización deste tipo é a posibilidade de recupera-la información almacenada. Esta recuperación pódese efectuar desde perspectivas diversas e con distintos instrumentos. Cabe esperar que se busquen mesmo respostas a preguntas que a ninguén se lle ocurriran durante o proceso de almacenamento. Por eso, parece que unha base de datos capaz de manipula-las estructuras definidas é o instrumento idóneo para garantir todo tipo de investigacións; mediante buscas combinadas de elementos diversos, pódense obter automáticamente resultados que, manualmente, nalgúns casos serían inalcanzables. Esa é a razón de que se empregue un sistema de xestión de bases de datos relacional que permita tratar documentos en SGML e que aporte unha linguaxe de interrogación que axilice as buscas. Ademáis deste sistema de xestión, precísase un contorno de recuperación que facilite o acceso á información almacenada nas bases de datos.

De tódolos xeitos, esta recuperación selectiva da información non é máis ca unha das posibilidades de explotación que o futuro sistema ofrecerá como resultado do proxecto. Poderase traballar desde o propio contorno, nunha rede local, ou accedendo a partir de calquera rede externa. Pero, desde que se ideou o proxecto, considerouse necesario ofrecer outras posibilidades de aproveitamento dos resultados, entre elas a publicación en texto impreso das distintas seccións dos traballos, a creación dun ou varios CD-ROMS, a consulta a través de Internet, etc. En calquera caso, a codificación da información é a única técnica que pode garanti-lo cumprimento das esixencias dos usuarios.

\section{ESTADO ACTUAL DO PROXECTO}

Nestes momentos (decembro de 1997), están resoltos bastantes dos problemas que foron xurdindo a medida que avanzaba o deseño do proxecto. Por 
unha parte, e aínda que non se realizase todavía a dixitalización dos cancioneiros, están xa tramitados os permisos preceptivos e disponse de case tódalas diapositivas solicitadas. Por outra, despois de moitas adaptacións e modificacións, atopouse un modelo de estructuras que parecen aptas para a obtención dos fins propostos.

A DTD utilizada ten dúas versións compatibles, necesarias para dar conta da propia realidade dos textos: nunha delas estanse introducindo os datos que se fixeron públicos mediante a edición dos dous volumes da Lírica profana galego-portuguesa, así coma outros elementos que non se recollían explicitamente nesa publicación; están xa etiquetadas máis de oitocentas cantigas. $\mathrm{Na}$ segunda versión, que supón unha obrigada reducción de elementos "marcados", porque as edicións críticas existentes non se axustan a unha mesma estructura preestablecida, estase a traballar na universidade de Barcelona baixo a supervisión directa do Prof. Vicente Beltrán.

Ademáis, decidiuse ofrecer en rede una versión lixeiramente simplificada dos datos que figuran no libro impreso, e estase procedendo xa a efectua-los últimos axustes e correccións.

A estructura dos campos correspondentes ás biografías dos trobadores contén os seguintes datos: número do trobador, nome, orixe (con indicación expresa da fiabilidade da orixe proposta), condición social, período de actividade, e, finalmente, reproducción do texto da biografía tal e como figura na edición do CIRP.

Pola súa banda, os campos sinalados para as cantigas son: número da cantiga, incipit, nome do trobador, referencias dos manuscritos, relacións interestróficas (este campo, igual que algúns dos que seguen, exprésase con valores codificados, dos que se facilitará a oportuna táboa), recursos retóricos, xénero, modalidade xenérica, modalidade compositiva, rúbrica, esquema rimático, número do esquema no $R M$ de Tavani, indicación da existencia ou non de fiin$d a$, ou de tensó, edición seguida, número do trobador, texto da cantiga.

Para cada un dos campos relacionados, poderase buscar un valor, ou varios valores, especificando se hai que atopalos todos ou só algún deles, e se hai que ter en conta ou non a orde dos valores especificados; tamén se poderá buscar por rangos, ou por patróns, por palabras ou frases, etc. Combinando as buscas, pódese lograr que o sistema busque por varios campos á vez, especificando se se teñen que cumprir tódalas condicións ou só algunha delas. A saída poderase ordenar de maneira ascendente ou descendente por cada campo.

Está prevista unha pantalla de axuda onde se pode botar unha ollada ós índices dos campos, é dicir, consultar unha lista ordenada dos diferentes valores de cada un dos campos que levan índice (todos, ergas o de "edición seguida"), con información do número de ocorrencias do valor e o número de documentos nos que se pode atopar ese valor. Así mesmo, pódese seleccionar un destes valores e obter por ese medio os documentos nos que aparece ese valor. 